\title{
Temporal and Spatial Distribution of the Oriental Beetle (Coleoptera: Scarabaeidae) in a Golf Course Environment
}

\author{
HENRY T. FACUNDO, ${ }^{1}$ MICHAEL G. VILLANI, CHARLES E. LINN, JR., AND \\ WENDELL L. ROELOFS ${ }^{2}$
}

Department of Entomology, Barton Laboratory, NYSAES, Cornell University, Geneva, NY 14456

\begin{abstract}
Environ. Entomol. 28(1): 14-21 (1999)
ABSTRACT The mating season of the oriental beetle, Exomala orientalis (Waterhouse), in 1994 and 1995 at Bethpage State Park, Farmingdale, NY $\left(40^{\circ} 45^{\prime} \mathrm{N}, 73^{\circ} 28^{\prime} \mathrm{W}\right)$ began in the middle of June, peaked in the 1st wk of July, and ended in the middle of August. There were differences in the emergence schedule among fairways as well as local differences between roughs and fairway. Both sexes were most active around sunset on shorter-cut turf (i.e., fairways, greens, and tees, versus roughs), and the few individuals seen during the daylight hours were mostly males. These males were generally found perched on vegetation at the border of the fairway. Feeding was not observed, except on flowers by females devoid of mature eggs. This study confirms our observations on the pattern of activity in an earlier study conducted with the use of synthetic pheromone traps. It also explains the difficulty encountered by earlier workers in finding adults of this insect in the field. Implications of the above findings on the management of the oriental beetle are discussed.
\end{abstract}

KEY WORDS Exomala orientalis, temporal and spatial distribution, golf course

The ORIENTAL BeEtLe, Exomala orientalis (Waterhouse) (=Anomala orientalis) (Coleoptera: Scarabaeidae: Rutelinae), has become the most important grub pest of turf and woody ornamental plantings in the Long Island region of New York, northern New Jersey, and Connecticut. However, because of its relatively limited range and the cryptic nature of the adults, the oriental beetle has not gained notoriety status like that of the more ubiquitous and conspicuous turf pest the Japanese beetle, Popilla japonica Newman (Scarabaeidae: Rutelinae). Oriental beetle grub damage in the Northeast is still often attributed to other species, especially the Japanese beetle. Currently, Japanese and oriental beetle grubs are managed similarly because of the similarity between their life cycles (Alm et al. 1995). However, differential susceptibility of Japanese and oriental beetle grubs to soil insecticides (Villani et al. 1988) and an insect growth regulator (Cowles and Villani 1996) have been documented. This underscores the need for accurate identification of the pest causing the problem to efficiently and effectively use insecticides or other control measures for environmental as well as economic reasons.

The identification and synthesis of the female sex pheromone of the oriental beetle (Leal 1993, Zhang et al. 1994) has led to the development of an effective synthetic pheromone trap that has greatly facilitated monitoring and detection of oriental beetle populations. Facundo et al. (1994) demonstrated the pher-

\footnotetext{
${ }^{1}$ Current address: Department of Entomology, University of the Philippines Los Baños, College, Laguna 4031, Philippines.

${ }^{2}$ To whom reprint requests should be sent.
}

omone's potency by catching an average of 1,000 male beetles per trap per day in 2 golf course fairways in Norwich, CT, using a 100- $\mu$ g dosage of either (Z) -7tetradecen-2-one or an 89/11 (Z/E) blend on a rubber septum. It was further determined that $10 \mu \mathrm{g}$ was the minimum concentration with which no significant decrease in catch was observed. Before the development of a pheromone trap, soil sampling for grubs was the only way to confirm the presence of this species. Grubs found in soil samples have to be identified by examining rastral patterns (arrangement of spines, hairs, and bare spaces at the ventral area of last abdominal segment just anterior to the anus), which is the only reliable way to distinguish oriental beetle grubs from other turf-infesting scarabs (Tashiro 1987).

In lieu of a pheromone detection system, scouting for adults may be a viable alternative if the ecology of the adults is well understood. Additionally, knowledge of the adult's natural history and behavior may lead to more effective use of the synthetic pheromone for the management of this insect.

The current study was conducted to document activities of oriental beetle adults in a golf course environment during summer at Bethpage State Park, Farmingdale, NY. This environment is in contrast to earlier reports of scouting in home lawns in New Haven, CT, by Friend (1929) and those in southeastern New York by Hallock (1930), and observations done by Bianchi (1935) in sugarcane fields of the Oahu Sugar Company in Oahu, HI. Specifically, the current study addressed the following 4 questions: (1) What is the seasonal and daily pattern of adult emergence from the soil? (2) Does this insect exhibit protandry 
or protogyny? (3) Where are adults found at different times of the day and what are their behaviors? (4) Are there differences between the sexes in terms of daily as well as seasonal activities? (5) What is the abundance and distribution of each of the immature life stages found in the soil during summer?

\section{Materials and Methods}

Study Site. Unless otherwise noted, all field observations and sampling were done at the 14th hole of the Green course of Bethpage State Park, Farmingdale, $\mathrm{NY}\left(40^{\circ} 45^{\prime} \mathrm{N}, 73^{\circ} 28^{\prime} \mathrm{W}\right)$. The fairway measured $180 \mathrm{~m}$ long by $28 \mathrm{~m}$ wide with $>10 \mathrm{~m}$ wide roughs areas at both sides. One side of the fairway was bordered by another fairway and the other by thick vegetation composed of bushes, shrubs, and trees. Both the fairway and roughs are composed of a combination of several grass species: perennial ryegrass (Lolium perenne L.), Kentucky bluegrass (Poa pratensis L.), annual bluegrass ( $P$. annua L.), and chewing fescue (Festuca rubra commutata Gand.), with cutting heights at 1.6 and $4.3 \mathrm{~cm}$, respectively.

Emergence Cones. Nine screened wire-mesh emergence cones $(0.6 \mathrm{~m}$ basal diameter and $1.0 \mathrm{~m}$ high) were positioned, at least $10 \mathrm{~m}$ apart, at the roughs along one side of the fairway on 29 June 1994. Care was taken to ensure that the edges in contact with the turf were sealed to prevent beetle escape. The cones were monitored daily at 1000, 1400, 1800, and 2100 hours from 30 June to 16 July 1994. An additional 9 cones were similarly set up at the roughs of a 2nd fairway (site 2$) \approx 250 \mathrm{~m}$ from the 1st. These were monitored immediately after the first 9 were checked. Monitoring of each site took $\approx 30 \mathrm{~min}$.

Turf and Soil Sections. Each day from 1 to 16 July 1994, $5-9$ soil sections ( 0.3 by 0.3 by $0.2 \mathrm{~m}$ ) were sampled around randomly chosen emergence cones (see above) at the 1st site. Each section was removed $\approx 1-\mathrm{m}$ radius around a cone at 1 of 8 compass points. All samples on a given day were taken at the same compass direction. Each section was inspected at 2.5-cm depth intervals at a time for presence of all developmental stages of the oriental beetle. The location in the soil of each individual was recorded and all individuals were kept in separate 29.6-ml cups with soil for later species identification (upon reaching the adult stage).

Fifteen-Minute Random Walk. To determine the seasonal flight pattern, a 15-min random walk was executed daily at 2130 hours from 29 June to 17 July 1994 to sample the adult population present on the fairway surface. Based on pheromone trap catch, adult activity is highest at 2100 hours or around sunset (Facundo et al. 1994). Monitoring was done by walking through the fairway, turning at randomly chosen points, with the aim of covering the entire fairway within the 15-min period. All oriental beetle adults encountered during the walk were captured and placed in a resealable plastic bag for gender determination and total count.
Five-Minute Random Walk. To determine the daily activity pattern, similar but shorter (5 min) random walks were undertaken at 1000, 1400, 1800, and 2300 hours on 1-17 July 1994. Effort was made to ensure that the entire fairway was monitored. The 2100 hours beetle count reflected in Fig. 3 was intrapolated from the 15-min random walk data by dividing the number of beetles found on corresponding dates by 3 .

Vegetation Visits. The vegetation at the border of the roughs where the emergence cones were set up was inspected for presence of oriental beetles at 1000 , 1400,1800 , and 2200 hours on 1-5 July 1994. Each beetle's sex, position on the plant, posture, pairings, and activities such as resting, antennae waving, and feeding were recorded.

Pheromone Trapping. To determine the onset of the flight season, a Trece JB trap (Salinas, CA) baited with $10 \mu \mathrm{g}$ of $(Z)$-7-tetradecen-2-one on rubber septum (Thomas Scientific, Swedesboro, NJ) and positioned such that the mouth of its funnel was at ground level was installed at site 2 during the 1st wk of June in 1994-1996. The trap was monitored daily until the 1 st beetles were caught. Temperature data were obtained from the Nassau County Department of Public Works weather station in Mineola, NY (15 km west of Bethpage State Park), to compute for degree-day accumulation at $10^{\circ} \mathrm{C}$ base temperature. To determine the seasonal flight pattern using synthetic pheromone, 6 traps were installed in 6 different fairways at 2 adjacent golf courses. Monitoring was done at 0800 hours daily from 19 June to 19 July 1995 . Beetles caught in each trap were poured into individual resealable plastic bags for later counting. Baits were changed every other week.

Transect. A 312-m transect was set up across the roughs, fairway, litter, bare soil, and other vegetation (bushes, shrubs, trees) of hole 13 of the Black course (site 3). In addition, to naturally occurring flowers of grasses and weeds, 2 small artificial flower patches composed of roses, chrysanthemum, petunia, and other annuals were set up. Oriental beetles found within $1 \mathrm{~m}^{2}$ by walking along this transect at 1000 , $1200,1500,1800,1900,2000,2100,2200,2300$, and 2400 hours on 21 and 26 June and 6, 8, and 18 July 1995 were noted in terms of sex, position on the plant, posture, and activities. The following are the total areas covered by each vegetation type in square meters: fairway $=104$, roughs $=99$, tall grass $=23$, shrub $/$ bush $=$ 50 , tree (mostly white pine) $=13$, flower $=11$, and litter/bare soil $=12$. The total number of males and females found per area covered by each vegetation type was later computed and compared using 2-way analysis of variance (ANOVA) with time of day as the 2nd factor.

Sampling for Pupae. To test for the occurrence of protandry in this insect, 15 additional turf and soil sections (as described above for 1994, but only up to a depth of $10 \mathrm{~cm}$ ) were sampled on the edges of the fairway of site 2 on 10 and 17 June 1996 (i.e., 5 d before and $2 \mathrm{~d}$ after the 1st male was caught in 1996, respectively). Pupae found were sexed, whereas larvae were 


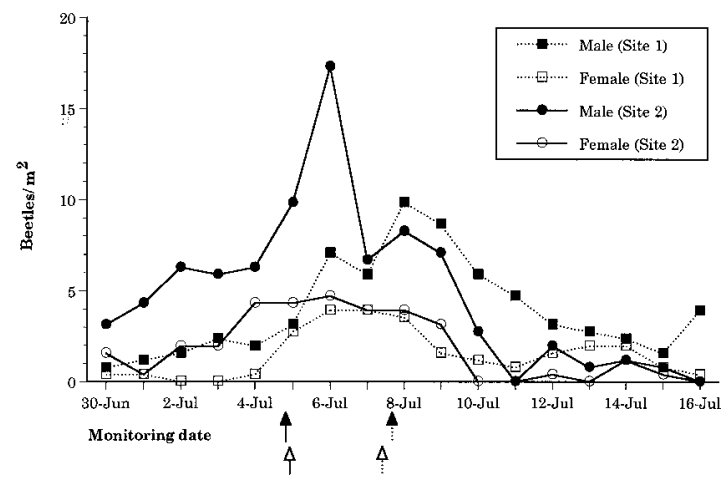

Fig. 1. Beetles collected from emergence cones set in the roughs areas of 2 sites at Bethpage State Park, Farmingdale, NY, in 1994. Arrows at the bottom indicate the dates when median catch was reached for each site and sex.

reared in 29.6-ml cups with soil for later sex determination.

Statistical Analyses. Data from the emergence cones, 5-min random walk, and vegetation visits were analyzed separately using the Wilcoxon signed-rank test for the difference between sexes at each monitoring time, and the Friedman test for differences among times of day for each sex (Conover 1980). Standard error was computed and shown in graphs where appropriate.

Other Locations. The rose gardens of Planting Fields Arboretum, Planting Fields, NY, and Pinelawn Cemetery, Farmingdale, NY, were inspected for the presence of oriental beetle on roses on 15 and 17 July 1995, respectively. Activities such as feeding, mating, and resting on the flowers were recorded before collecting the beetles. All females found were later dissected for oviposition status.

Emergence Pattern in the Laboratory. Third-instar grubs collected from Bethpage on 8 September 1996 were individually placed in $29.6-\mathrm{ml}$ cups with soil and grass seeds. These were stored at $10^{\circ} \mathrm{C}$ and transferred by batch of 150 individuals to $25^{\circ} \mathrm{C}$ on 19 February and $26 \mathrm{March}$ 1997. Each cup was inspected for pupae $3 \mathrm{wk}$ after the transfer to $25^{\circ} \mathrm{C}$ (16:8 [L:D] h) and each week thereafter. The pupae were inspected daily to closely monitor eclosion. Male and female eclosion patterns were compared using Kolmogorov-Smirnov test at $\alpha=0.05$ (Siegel 1956).

\section{Results}

\section{Seasonal Pattern}

Difference Between and within Sites. The 1st male was caught in synthetic pheromone traps on the 16th of June 1994, the 12th of June 1995, and the 15th of June 1996 at Bethpage State Park (357.2, 307.5, and 357.5 DD, respectively). The pattern of emergence was unimodal with the peak occurring in the 1st half of July (Figs. 1 and 2). However, there was significant variation between adjacent areas (Fig. 1) and even

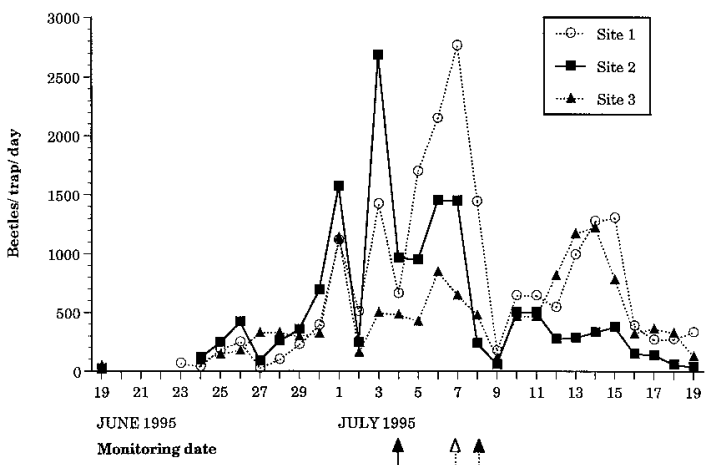

Fig. 2. Beetles caught (mostly males) in synthetic pheromone traps in 3 sites at Bethpage State Park, Farmingdale, NY, in 1995. Arrows at the bottom indicate the dates when median catch was reached for each site; trap was not installed on 19-22 June at site 1, and 20-23 June at sites 2 and 3.

local differences among areas that were managed differently, such as the roughs versus the fairway (Fig. 1 versus Fig. 3). Data from emergence cones indicate that the 2nd site had a significantly earlier peak than the 1st (Fig. $1 ; t$-test on median, $P<0.0001$ ). Fig. 3 presents data from the 15-min random walk in the fairway of the 1st site. Although no direct statistical comparison can be made between data collected using 2 sampling methods, it can be noted that the median dates of both males and females in the fairway (4 July; Fig. 3) were $4 \mathrm{~d}$ earlier than those of the roughs (8 July; Fig. 1). This suggests localized differences within a small area perhaps the result of local heterogeneity in vegetation type, grass height, soil moisture, and soil type.

The 1995 pheromone trapping supports the apparent difference in the emergence schedule between the 2 sites (Fig. 2). The median dates were 7 July and 4 July for 1st and 2nd site, respectively, as in the 1994 season. For additional comparison, 1 other site (hole 13 of the Black course) was included in the graph. This

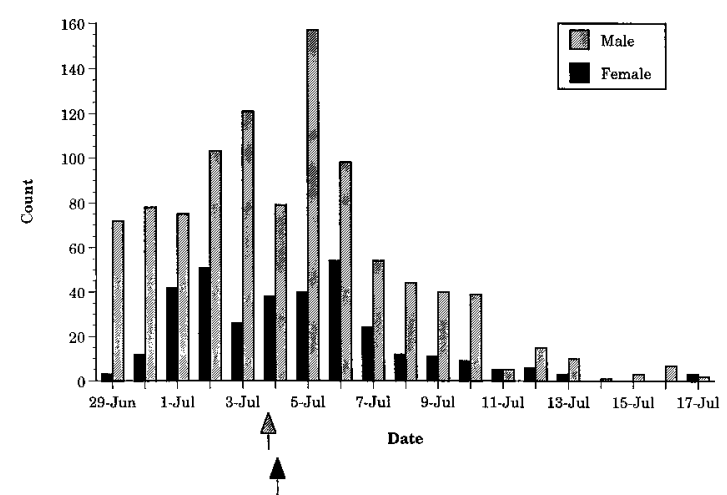

Fig. 3. Number of beetles encountered at the fairway of site 1 during 15-min random walks at 2130 hours. Arrows at the bottom indicate the dates when median of the total number of individuals collected during the monitored season was reached for each sex. 


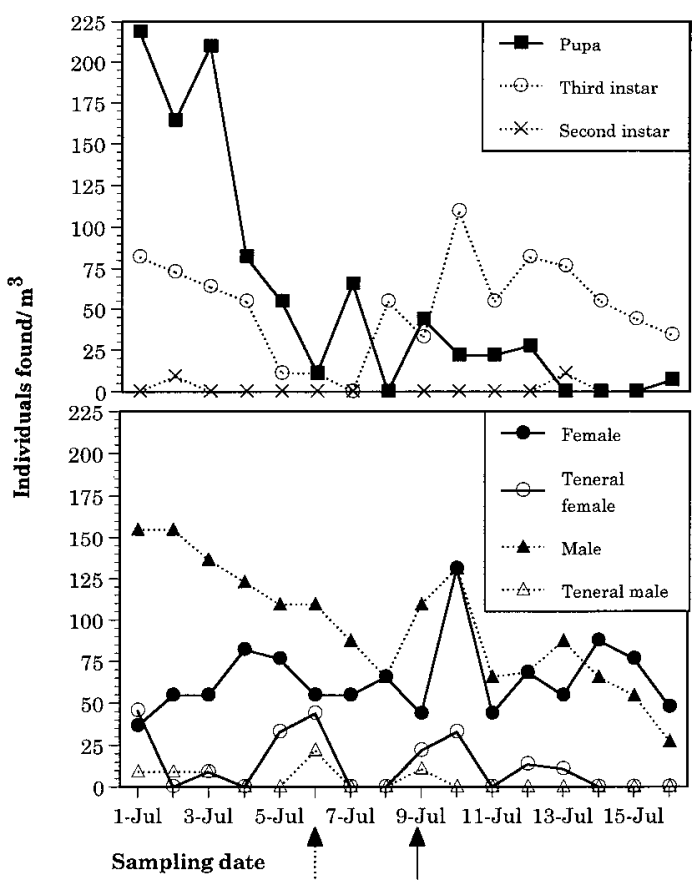

Fig. 4. Daily cumulative adult eclosion in the laboratory at $25^{\circ} \mathrm{C}$ of 2 batches of 150 grubs collected on 8 September 1996 at Bethpage State Park, Farmingdale, NY. Total number of eclosed males and females for batch 1 were 20 and 19 , respectively; and 20 and 12, respectively, for batch 2 . Male and female distributions were significantly different for the 2 batches $(P<0.001$ and $P<0.01$, respectively) using the Kolmogorov-Smirnov test. Arrows at the bottom indicate the dates when median of the total number of individuals that eclosed was reached for each sex and batch.

site is $\approx 2 \mathrm{~km}$ away from either of the 2 main sites and had a median date $1 \mathrm{~d}$ later than site 1 .

Protandry. The daily cumulative adult eclosion pattern of 2 batches of oriental beetle grubs reared in the laboratory are indicative of protandry (Fig. 4). The 1st individuals to reach the imaginal stage in each batch were males. The 1st male to eclose for batches 1 and
2 were 8 and $11 \mathrm{~d}$, respectively, earlier than their respective 1st females. The average number of days when $50 \%$ of males reached adulthood is $9 \mathrm{~d}$ earlier than females (for details refer to location of arrows in Fig. 4).

Sampling for pupae in 1996 immediately before and during the start of adult emergence has yielded data verifying the trend observed in the laboratory (Table $1)$. Before the mating season (10 June), significantly more male pupae $\left(274.11 \pm 186.67 / \mathrm{m}^{3}\right)$ than female pupae $\left(96.33 \pm 92.22 / \mathrm{m}^{3}\right)$ were unearthed; whereas, 1 wk later during the start of the mating season, there was no significant difference between the 2 pupae populations $\left(251.89 \pm 49.00\right.$ versus $229.67 \pm 33.33 / \mathrm{m}^{3}$, respectively). The only adult beetles found in the soil on the 17 June 1996 sampling were males (Table 1).

In 1994, data on the males and females and teneral adults sampled in the soil during the mating season are indicative of protandry as well. The date when half of all mature males unearthed throughout the monitored season were found was $3 \mathrm{~d}$ earlier than that of females (6 and 9 July, respectively; Fig. 5). More males were found at the onset of the monitored season, and then the sex ratio changed to $\approx 50: 50$. In contrast, more teneral females than teneral males were found throughout the monitored season (Fig. 5).

Differences Among Developmental Stages. Fig. 5 shows the mean number of each developmental stage found in the soil blocks sampled around the cones. There was a dramatic decrease in the number of pupae sampled after 3 July 1994, followed by an increase in the number of teneral adults. Third instars were present throughout the monitored season, the late ones presumably overwintering the 2 nd time (2-yr cycle; Tashiro 1987). Only three 2nd-instar grubs were found.

\section{Daily Pattern}

Time of Day. Significantly more males and females were collected in the emergence cones at 2100 hours than at any other time (Fig. 6). Data from 5-min random walks in the fairway of site 1 at different times

Table 1. Mean number of males and females of each stage sampled before and during the start of adult emergence at Bethpage State Park, Farmingdale, NY (date of lst male caught in pheromone trap is 15 June 1996)

\begin{tabular}{|c|c|c|c|c|}
\hline \multirow{2}{*}{ Sampling date } & \multicolumn{4}{|c|}{ *Mean no. $/ \mathrm{m}^{3}$} \\
\hline & Adults $^{a}$ & Pupae & Prepupae & Larvae \\
\hline \multicolumn{5}{|l|}{10 June 1996} \\
\hline Male & 0 & $274.11 \pm 186.67 \mathrm{a}$ & $22.22 \pm 11.89 \mathrm{a}$ & $22.22 \pm 11.89 \mathrm{a}$ \\
\hline Female & 0 & $96.33 \pm 92.22 b$ & $14.78 \pm 10.11 \mathrm{a}$ & $29.67 \pm 13.11 \mathrm{a}$ \\
\hline Unknown sex ${ }^{b}$ & - & $96.33 \pm 151.11$ & $281.44 \pm 38.89$ & $103.67 \pm 29.67$ \\
\hline \multicolumn{5}{|l|}{17 June 1996} \\
\hline Male & $22.22 \pm 11.89 a$ & $251.89 \pm 49.00 \mathrm{a}$ & 0 & $7.44 \pm 7.44 \mathrm{a}$ \\
\hline Female & $0 \mathrm{~b}$ & $229.67 \pm 33.33 \mathrm{a}$ & 0 & $22.22 \pm 11.89 \mathrm{a}$ \\
\hline Unknown sex ${ }^{b}$ & - & $14.78 \pm 10.11$ & $51.89 \pm 18.33$ & $29.67 \pm 13.11$ \\
\hline
\end{tabular}

Means followed by the same letter for each stage and sampling data are not significantly different (paired $t$-test, $\alpha=0.05$ ).

${ }^{a} P=0.082$ for male versus female adults sampled on 17 June 1996.

${ }^{b}$ All pupae whose sex were undetermined were crushed during sampling in the field. All prepupae whose sex were undetermined died before reaching the pupal stage during laboratory rearing. Fourteen and $25 \%$ of larvae whose sex were undetermined for 10 and 17 June, respectively, were crushed during sampling, and the rest died during laboratory rearing without reaching the pupal stage. 


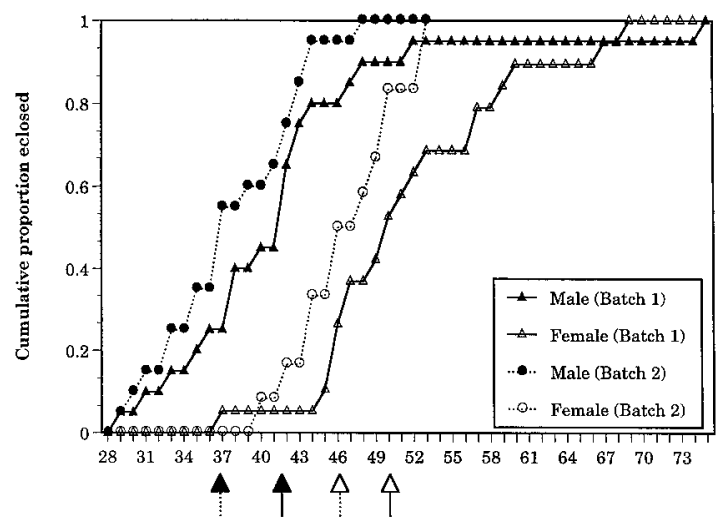

Days after transfer to $25^{\circ} \mathrm{C}$

Fig. 5. Soil sampling data showing counts of individuals of different developmental stages found throughout the monitored season. Arrows at the bottom indicate the dates when half of the mature males and females unearthed throughout the monitored season were found.

of the day also showed this pattern (Fig. 7) and is consistent with a previous study (Facundo et al. 1994) in which pheromone and blacklight traps were used. In surrounding vegetation (bushes, shrubs, and trees), however, there was no significant differences in the number of beetles present at different times of the day (Fig. 8). Observations and data on the 1995 transect at a different site corroborate the 1994 data. The 1995 transect data confirmed that the oriental beetle is a crepuscular/nocturnal insect, being most active at the first $2 \mathrm{~h}$ of the scotophase (Friedman test, $P<0.05$ ). The above-mentioned difference between beetle presence in fairways versus surrounding vegetation will be discussed in the section on spatial distribution.

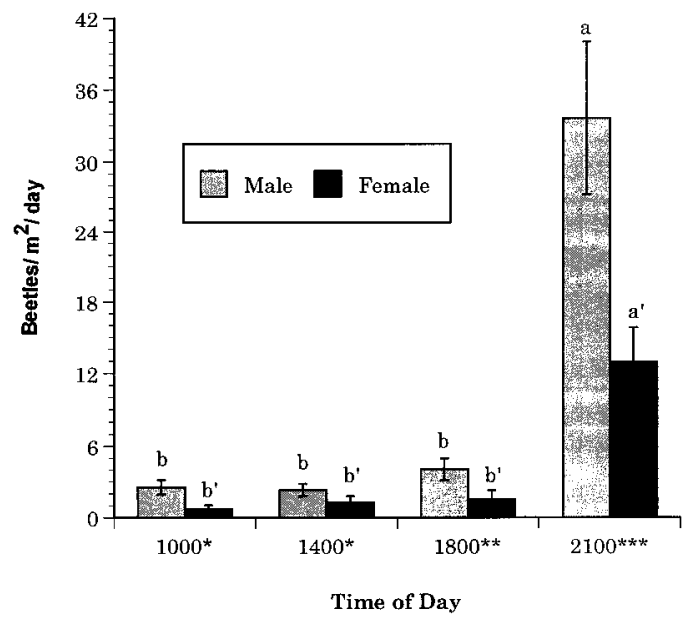

Fig. 6. Beetles collected from emergence cones at different times of the day from 30 June to 16 July 1994. Bars of the same kind with the same letter (and superscript) are not significantly different at $\alpha=0.001$. For comparison between sexes: *, $P<0.05$; **, $P<0.01$; ***, $P<0.001$.

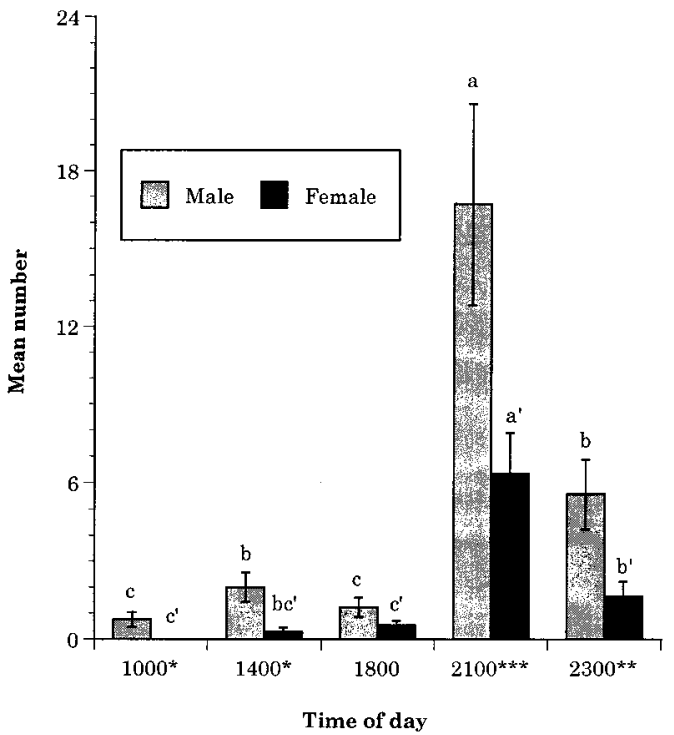

Fig. 7. Number of beetles encountered in 5-min random walks on the fairway of site 1 in 1994. Bars of the same kind with the same letter (and superscript) are not significantly different at $\alpha=0.05$. For comparison between sexes: *, $P<$ 0.05 ;*,$P<0.005$; ***, $P<0.001$.

Difference Between Sexes. One obvious difference between males and females is the greater presence of males at all times in both the fairway (Fig. 7) and the surrounding vegetation (Fig. 8). Male beetles perch on surrounding vegetation mostly within the 1st $\mathrm{m}$ from the ground. Feeding by males was rarely ob-

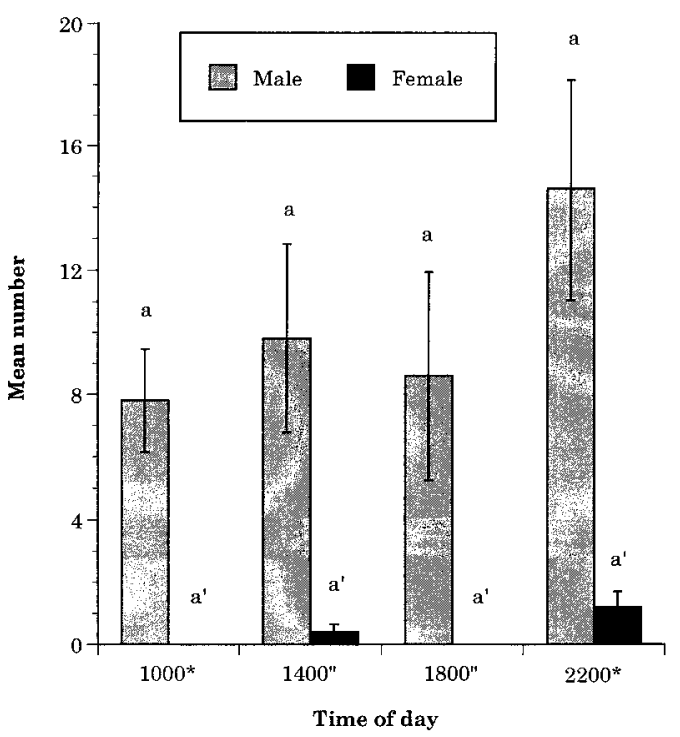

Fig. 8. Number of beetles encountered during visual inspection of vegetation on the border of site 1 in 1994. Bars of the same kind with the same letter (and superscript) are not significantly different at $\alpha=0.05$. For comparison between sexes: *, $P<0.05$; ", $P<0.068$. 


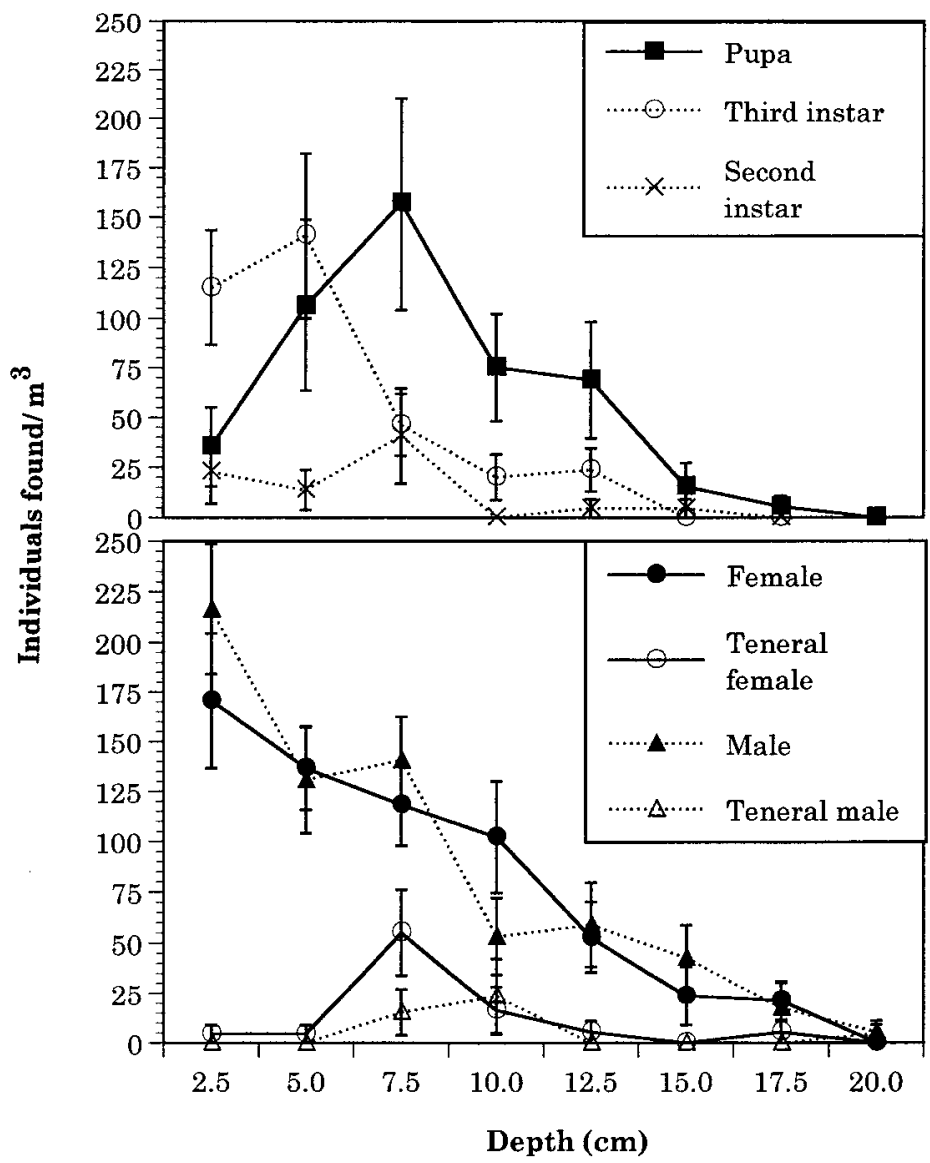

Fig. 9. Soil sampling data showing counts of various stages found within different depths.

served and mating was not observed on surrounding bushes, shrubs, or pine trees.

Females, by comparison, were rarely seen perched on nearby vegetation. The small number seen during the day were mostly on turf and this number slowly increased to a peak at around sunset. Females are behaviorally more cryptic, emerging from the soil when light intensity decreases and immediately going back to soil after mating (H.T.F., unpublished data; also observed in the laboratory, see Facundo et al. 1999).

\section{Spatial Distribution}

Most individuals unearthed in all developmental stages were within $10 \mathrm{~cm}$ from the surface (Fig. 9). Second-instar grubs were found at the first $7.5 \mathrm{~cm}$ of the soil profile. Although 3rd-instar grubs were mostly in the upper $5.0 \mathrm{~cm}$, many were also found below 5.0 $\mathrm{cm}$. This 3rd-instar population may be composed of those still feeding within the root zone at the first 5.0 $\mathrm{cm}$, and those moving down to pupate. Pupae, however, seem to prefer the portion of the soil profile $>2.5-12.5 \mathrm{~cm}$. As expected, teneral adults were found at depths $>5.0-10.0 \mathrm{~cm}$, which is within the zone where most pupae were located. Adults were found within the upper half of the sampled profile (Fig. 9).

Above ground, males are more likely to be found on fairways at around dusk, and on bushes, shrubs, and low-growing plants at the border of the course throughout the day (Fig. 10, see also Figs. 7 and 8). While perched, they stay on leaves of low-growing plants (as well as leaves or needles of trees) within $0.3-1.0 \mathrm{~m}$ high. Females, however, are generally only visible around sunset and are found more in the fairway than in any other part of the golf course environment (Figs. 10 and 7 and 8). Most pairings occur on fairways and areas with shorter-cut turf and coincides with this female emergence from the soil.

Adults found feeding and perched on flowers, especially roses and chrysanthemum, were mostly females. Although no statistical difference exists between the sexes on flowers in the transect data (Fig. 10), collections in the rose gardens of Pinelawn Cemetery ( 45 females out of 51 individuals found on roses) and of Planting Fields Arboretum (14 out of 16) confirm the sex bias. Dissection of the reproductive tracts revealed that the majority of females found on roses did not have mature eggs, indicating that these were older females who had oviposited (mean mature eggs 


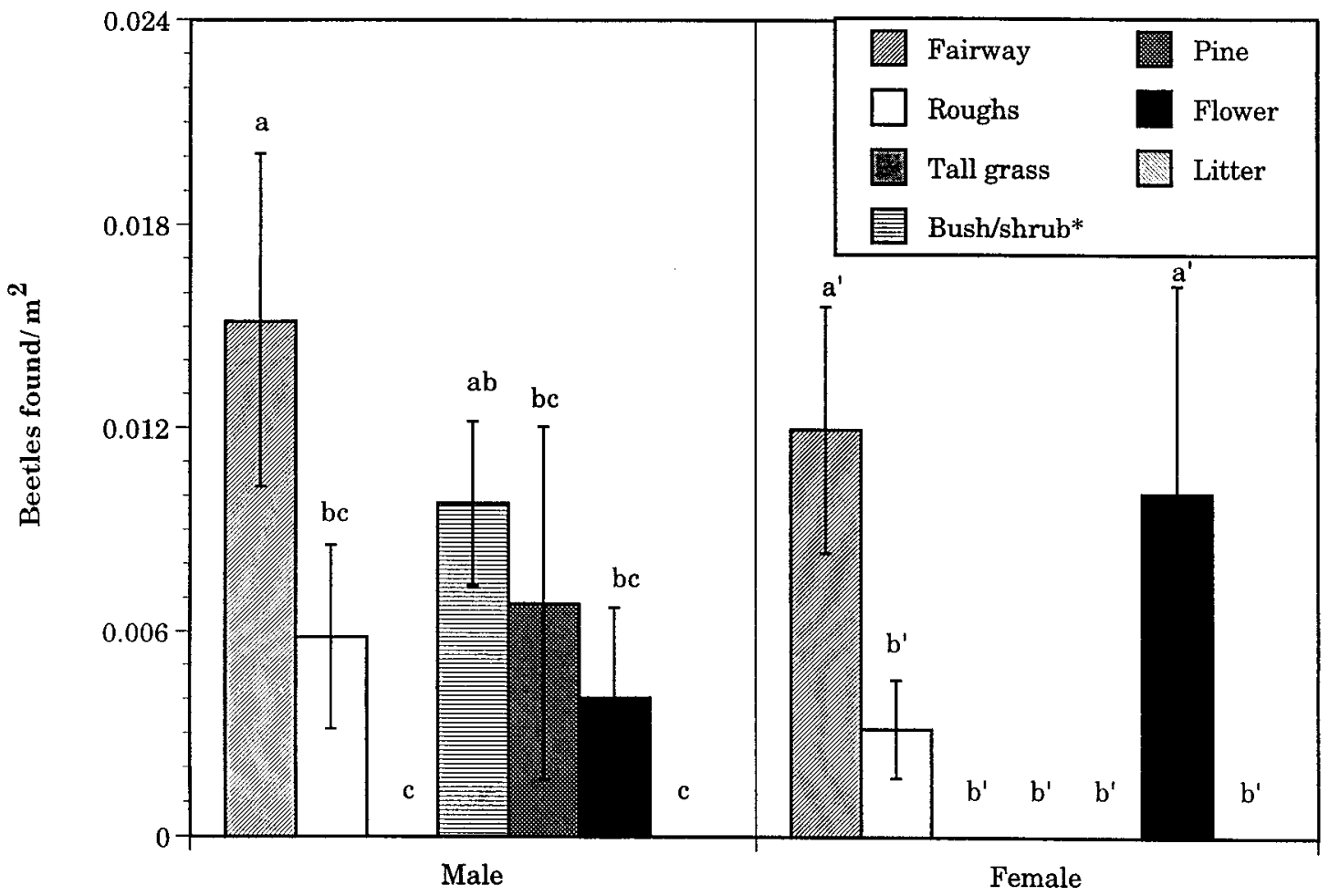

Fig. 10. Standardized transect data showing relative abundance of oriental beetles at different area (vegetation) of site 3 in 1995. Bars with the same letter (and superscript) are not significantly different at $\alpha=0.05$. For comparison between sexes at specific vegetation type: ${ }^{*}, P<0.05$.

per female $=1.53 ; n=45$; range $0-14$; versus 21.2 eggs per female in virgin females, $n=10$; range, 13-37; Facundo 1997).

\section{Discussion}

In this study, the mating season of the oriental beetle at Bethpage commenced in mid-June, peaked during the 1st half of July, and decreased toward midAugust. There was a significant difference ( $4 \mathrm{~d}$ at most, based on dates of median catch) in emergence schedules between fairways and even within a local area (e.g., the fairway versus the roughs). This variation may be of importance in planning sampling and control techniques involving pheromones. A case in point is the use of this pheromone to predict grub density in the subsequent fall. If shorter term adult sampling during the summer using synthetic pheromone is preferred over season-long sampling, a 4-d difference in emergence pattern between fairways can potentially complicate the analysis of a single day sampling or reduce its predictive value. Therefore, a nightly trapping schedule that spans this difference (e.g., 4 successive nights of trapping) might be essential to dilute such discrepancies and in effect make the emergence schedule in different locations more uniform.

A major goal of the current study was to examine the temporal and spatial distribution of beetles without using the synthetic pheromone. In terms of daily ac- tivities, although earlier workers reported that nocturnal activities occur (Johnson 1927, Friend 1929), the general perception has been that the beetle is most active during the day, with most flights occurring between 0800 and 1600 hours, especially during very warm and sunny days (Hallock 1930, 1933). With the development of a synthetic pheromone trap, it has been demonstrated that the crepuscular and nocturnal movements are more important than previously thought, in that most flights occur around sunset ( Facundo et al. 1994). The current study supports the results obtained in 1993 (Facundo et al. 1994) in terms of the peak of daily activity, and it also explains the difficulty of earlier workers in finding the adults in the field. The relatively small number of flights observed during the day may be the result of male response to calling females or a response to high soil, thatch, and crown temperatures. In the case of the former, it is not uncommon to find males converging to a common point (a calling female), which may explain the instances when earlier workers found oriental beetles "swarming like bees over lawns" during the day (Hallock 1930). In the latter case, temperatures at ground level could be fatal during some parts of the day (e.g., $42.22 \pm 1.27^{\circ} \mathrm{C}$ at 1130 hours; Facundo 1997). Close observations showed that some males tend to stay at ground level within the thatch or crown area of the turf while extending their antennae to the air (also, Facundo et al. 1999). Similarly, females may call 
(with their posterior end up and head in the turf; see Facundo et al. 1999) during the day without being noticed if not for the presence of converging males.

The difference between males and females in terms of their behavior and spatial distribution with respect to vegetation type should facilitate identification and scouting. Both sexes are mostly found on short-cut turf especially around sunset. Males also are found perching on low-growing plants on the border of the course, whereas only females are found feeding on flowers.

The search for and feeding on flowers by oriental beetle females that had oviposited might be the only natural mode of dispersal of this species, especially because females generally call, mate, and deposit their eggs within a very small radius from the point of emergence from the soil (Facundo 1997, Facundo et al. 1999). Flowers apparently provide additional nutrients for a female's subsequent oviposition bout(s); as such, females were able to oviposit an additional $5.46 \pm 0.96$ fertile eggs (Facundo 1997). If this is the only natural mode of dispersal, then the natural spread of this beetle would be slow. This speculation is consistent with the observed general consistency and limited local infestation year after year and the beetle's present limited range in the United States (Facundo 1997). Bianchi (1935) also made such a supposition to explain the slow rate of spread of the oriental beetle in Hawaii, because he occasionally found females that were mostly devoid of mature eggs in copula on flowers that were removed from the focus of grub infestation in a sugarcane field. Hallock (1930) speculated that natural spread was slow because oriental beetles were rarely engaged in long flights and thus shipment of infested sod, rose blossoms with hidden females, and other infested plants with ball of earth was of considerable importance in the spread of this insect.

\section{Acknowledgments}

We thank Jim Evans and Bruce Lattmann of Bethpage State Park for their generous cooperation and ample tolerance to the inconveniences that go with researches like this. Tracy Wilson and a number of her crew are also acknowledged for their help in monitoring the traps. Maria Cinque and Kevin Masarik of the Cornell Cooperative Extension, Nassau County, also assisted in the monitoring of season-long traps in 1996. We also thank Patricia Duncan-Grady of Planting Fields Arboretum and Samuel Boiko of Pinelawn Cemetery for allowing us to conduct observations and collect grubs at those sites. Much gratitude is due to Dan Gilrein of the Long Island Horticultural Research Laboratory and Scott Clark of the Cornell Cooperative Extension, Suffolk County, for their help in the logistics. Loretta V. Dionisio of Nassau County Department of Public Works provided us with temperature data from 1994-1996. Charles Eckenrode lent us the emergence cones. Alison Power and Cole Gilbert are also hereby thanked for their comments and suggestions in the original manuscript. This study was funded in part by NEintegrated pest management grant no. 94-34103-0126 and a W. Arthur and Alma D. Rawlins Endowment to H.T.F.

\section{References Cited}

Alm, S. R., M. G. Villani, and M. G. Klein. 1995. Oriental beetle, pp. 81-83. In R. L. Brandenburg and M. G. Villani [eds.], Handbook of turfgrass insect pests. The Entomological Society of America, Lanham, MD.

Bianchi, F. A. 1935. Investigations on Anomala orientalis Waterhouse at Oahu Sugar Company, Ltd. Hawaii. Plant. Rec. 39: 234-255.

Conover, W. J. 1980. Practical nonparametric statistics, 2nd ed. Wiley, New York.

Cowles, R. S., and M. G. Villani. 1996. Susceptibility of Japanese beetle, oriental beetle, and European chafer (Coleoptera: Scarabaeidae) to halofenozide, and insect growth. J. Econ. Entomol. 89: 1556-1565.

Facundo, H. T. 1997. The reproductive ecology of the oriental beetle, Exomala orientalis (Waterhouse) (Coleoptera: Scarabaeidae). Ph.D. dissertation. Cornell University, Ithaca, NY.

Facundo, H. T., A. Zhang, P. S. Robbins, S. R. Alm, C. E. Linn, Jr., M. G. Villani, and W. L. Roelofs. 1994. Sex pheromone responses of the oriental beetle (Coleoptera: Scarabaeidae). Environ. Entomol. 23: 1508-1515.

Facundo, H. T., C. E. Linn, Jr., M. G. Villani, and W. L. Roelofs. 1998a. Emergence, mating and mate-locating behaviors of the oriental beetle, Exomala orientalis (Coleoptera: Scarabaeidae). Insect Behav. (in press).

Friend, R. B. 1929. The Asiatic beetle in Connecticut. Conn. Agric. Exp. Stn. Bull. 304: 585-664.

Hallock, H. C. 1930. The Asiatic beetle, a serious pest in lawns. U.S. Dep. Agric. Circ. 117: 7.

Hallock, H. C. 1933. Present status of two Asiatic beetles (Anomala orientalis and Autoserica castanea) in the United States. J. Econ. Entomol. 26: 80-85.

Johnson, J. P. 1927. Soil treatment and scouting for the control of the Asiatic beetle. J. Econ. Entomol. 20: 373-376.

Leal, W. S. 1993. (Z) - and (E)- Tetradec-7-en-2-one, a new type of sex pheromone from the oriental beetle. Naturwissenschaften 80: 86-87.

Siegel, S. 1956. Nonparametric statistics for the behavioral sciences. McGraw-Hill, New York.

Tashiro, H. 1987. Turfgrass insects of the United States and Canada. Cornell University Press, Ithaca, NY.

Villani, M. G., R. J. Wright, and P. B. Baker. 1988. Differential susceptibility of Japanese beetle, oriental beetle, and European chafer (Coleoptera: Scarabaeidae) larvae to five soil insecticides. J. Econ. Entomol. 81: 785-788.

Zhang, A., H. T. Facundo, P. S. Robbins, C. E. Linn, Jr., J. L. Hanula, M. G. Villani, and W. L. Roelofs. 1994. Identification and synthesis of female sex pheromone of oriental beetle, Anomala orientalis (Coleoptera: Scarabaeidae). J. Chem. Ecol. 20: 2415-2427.

Received for publication 23 September 1997; accepted 16 September 1998 . 